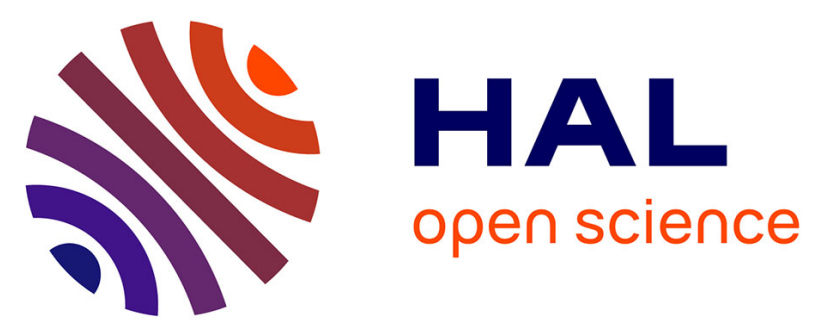

\title{
Ammonium Form of Nafion Plasticized by Dimethyl Sulfoxide
}

Ruslan Kayumov, Evgeny Sanginov, Lyubov Shmygleva, Alena Radaeva, Aleksander Karelin, Aleksander Zyubin, Tatiana Zyubina, Denis Anokhin, Dmitry Ivanov, Yury Dobrovolsky

\section{To cite this version:}

Ruslan Kayumov, Evgeny Sanginov, Lyubov Shmygleva, Alena Radaeva, Aleksander Karelin, et al.. Ammonium Form of Nafion Plasticized by Dimethyl Sulfoxide. Journal of The Electrochemical Society, 2019, 166 (7), pp.F3216-F3226. 10.1149/2.0261907jes . hal-02415157

\section{HAL Id: hal-02415157 https://hal.science/hal-02415157}

Submitted on 4 Jan 2021

HAL is a multi-disciplinary open access archive for the deposit and dissemination of scientific research documents, whether they are published or not. The documents may come from teaching and research institutions in France or abroad, or from public or private research centers.
L'archive ouverte pluridisciplinaire HAL, est destinée au dépôt et à la diffusion de documents scientifiques de niveau recherche, publiés ou non, émanant des établissements d'enseignement et de recherche français ou étrangers, des laboratoires publics ou privés. 
OPEN ACCESS

Ammonium Form of Nafion Plasticized by Dimethyl Sulfoxide

To cite this article: Ruslan R. Kayumov et al 2019 J. Electrochem. Soc. 166 F3216

View the article online for updates and enhancements. 


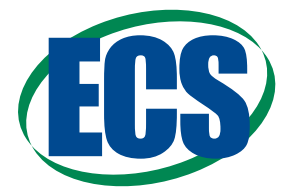

Jes Focus Issue on Advances in Modern Polymer Electrolyte Fuel Cells in Honor of Shimshon Gottesfeld

\title{
Ammonium Form of Nafion Plasticized by Dimethyl Sulfoxide
}

\author{
Ruslan R. Kayumov, ${ }^{1,2}$ Evgeny A. Sanginov, ${ }^{1,2}$ Lyubov V. Shmygleva, (1),2,z \\ Alena P. Radaeva, ${ }^{3}$ Aleksander I. Karelin, ${ }^{1}$ Aleksander S. Zyubin, ${ }^{1}$ Tatiana S. Zyubina, ${ }^{1}$ \\ Denis V. Anokhin, ${ }^{1,4}$ Dmitry A. Ivanov, ${ }^{1,2,4,5}$ and Yury A. Dobrovolsky ${ }^{1,2}$ \\ ${ }^{I}$ Institute of Problems of Chemical Physics of RAS, 142432 Chernogolovka, Moscow Region, Russia \\ ${ }^{2}$ Competence Center of National Technology Initiative in Institute of Problems of Chemical Physics of RAS, 142432 \\ Chernogolovka, Moscow Region, Russia \\ ${ }^{3}$ Lomonosov Moscow State University, 119991 Moscow, Russia \\ ${ }^{4}$ Moscow Institute of Physics and Technology (National Research University), 141700 Dolgoprudny, Russia \\ ${ }^{5}$ Institut de Sciences des Matériaux de Mulhouse, CNRS UMR 7361, F-68057 Mulhouse, France
}

\begin{abstract}
The work addresses the properties of electro-transport in highly ion-conductive polymer electrolytes based on Nafion-115 membranes in the $\mathrm{NH}_{4}{ }^{+}$ionic form plasticized with dimethyl sulfoxide (DMSO). The ionic conductivity and the activation energy of the conductivity were found to exhibit three types of behavior as a function of the plasticizer. The first region (when the ratio of moles of DMSO molecules per mole of $\left.\mathrm{NH}_{4}+(n)<6\right)$ is characterized by low conductivity values $\left(10^{-7}-10^{-4} \mathrm{~S} \mathrm{~cm}^{-1}\right)$ and high energy barriers $(0.76$ and $0.43 \mathrm{eV}$ for $n=0$ and 2.6, respectively). In the second region $(n=6-12)$, the electrolyte has a high conductivity and a low activation energy of conductivity $(\sim 0.1 \mathrm{eV})$. With an increase in the DMSO content, the conductivity appreciably increases and reaches $\sim 0.4 \mathrm{mScm}^{-1}$. In the third region $(n \geq 12)$ the transport parameters are comparable to those of the second region, but the conductivity is practically independent of the DMSO content. The observed behavior was explained on the basis of the results obtained with the help of IR spectroscopy, differential scanning calorimetry, small-angle X-ray scattering and quantum-chemical modeling.

(C) The Author(s) 2019. Published by ECS. This is an open access article distributed under the terms of the Creative Commons Attribution 4.0 License (CC BY, http://creativecommons.org/licenses/by/4.0/), which permits unrestricted reuse of the work in any medium, provided the original work is properly cited. [DOI: 10.1149/2.0261907jes]

(cc) BY
\end{abstract}

Manuscript submitted December 28, 2018; revised manuscript received April 1, 2019. Published April 29, 2019. This paper is part of the JES Focus Issue on Advances in Modern Polymer Electrolyte Fuel Cells in Honor of Shimshon Gottesfeld.

Ion-conductive polymer membranes constitute one of the key components of various solid state electrochemical energy conversion devices such as fuel cells, electrochemical sensors, metal-ion batteries). ${ }^{1-5}$ The polymer for such applications should exhibit high ion conductivity, thermal and chemical resistance and high mechanical strength. Among such materials, non-aqueous solid polymer electrolytes allowing transport of various cations $\left(\mathrm{Li}^{+}, \mathrm{Na}^{+}, \mathrm{Mg}^{2+}\right.$, etc.) are of considerable interest. ${ }^{6-13}$ From a fundamental point it is highly desirable to get insights into the processes of association and cation solvation, which directly affect the electrolyte transport properties. ${ }^{14-24}$ For the practical applications, new materials with high transport properties and a wide window of electrochemical stability are badly needed for creating more powerful and efficient electrochemical current sources, including using of active electrode materials $(\mathrm{Li}$, $\mathrm{Na}, \mathrm{Mg}$, etc.). ${ }^{2-5}$ Among solid polymer electrolytes, single-ion conductive polymers containing perfluorinate dionogenic groups such as $-\mathrm{CF}_{2} \mathrm{SO}_{3}$ - and $-\mathrm{SO}_{2} \mathrm{~N}-\mathrm{SO}_{2} \mathrm{CF}_{3}$ attract the greatest attention because they are most weakly coordinating anions providing high concentration of counterions in non-aqueous media and, accordingly, efficient ion transport. This feature of electrolytes is noticeably manifested in conditions of high concentration of ions when the ion association processes make an important contribution to the conductivity. In the literature, numerous reports have been devoted to lithium-ion transport in the Nafion-type membranes, which are promising single-ion conductive solid electrolytes for lithium-ion batteries. ${ }^{25-35}$ By contrast, studies on the transport of other ions are scarce. ${ }^{27,36-41}$ In this regard, it is worth to note that the membranes in ammonium form (Nafion$\mathrm{NH}_{4}$ ), which is plasticized with various anhydrous $(<1000 \mathrm{ppm}$ of water) aprotic solvents, including DMSO, have unusually high ion conductivity. ${ }^{27}$ The conductivity of such electrolytes significantly, 3 5 times, exceeds the conductivity of membranes in $\mathrm{K}^{+}$and $\mathrm{Rb}^{+}$forms (although radii of $\mathrm{K}^{+}$and $\mathrm{Rb}^{+}$comparable in radius to the ammonium one) and reaches the conductivity of membrane in the proton form. ${ }^{27}$ However, the reasons for the high conductivity of Nafion- $\mathrm{NH}_{4}$ are not fully elucidated. Higher value of ion conductivity of ammonium form

${ }^{\text {zE}}$-mail: shmygleval@mail.ru than for the alkali metal forms is also observed for the water-saturated membrane. But in this case, high conductivity is associated with a significant contribution of proton transport, although not to the same extent as for membrane in the proton form. Replacement of a proton to ammonium in the membrane leads to a significant about 3-4 times decrease in the conductivity. ${ }^{27,42-44}$ In addition, the Nafion- $\mathrm{NH}_{4} / \mathrm{DMSO}$ membrane can be considered as a simplified model of a more complex Nafion- $\mathrm{H}_{3} \mathrm{O}^{+} / \mathrm{H}_{2} \mathrm{O}$ membrane, in which the hydrated proton $\mathrm{H}_{3} \mathrm{O}^{+} \cdot(n$ $\mathrm{H}_{2} \mathrm{O}$ ) is replaced by an $\mathrm{NH}_{4}{ }^{+}$ion having a similar geometry, and water is replaced by DMSO also capable to form hydrogen bonds due to their lone pair of electrons, similar to water. This system allows carrying out a detailed experimental study as well as quantum-chemical modeling of ion transport processes at the molecular level, which makes it possible to expand insight in the proton transfer mechanisms in the more complex systems such as hydrated proton exchange membranes. In addition, according to our preliminary results, it was found that ion conductivity of the Nafion- $\mathrm{NH}_{4} / \mathrm{DMSO}$ membranes significantly depends on the ammonia concentration in the gas phase, and this membrane has a high ammonium permselectivity, which make them perspective materials as a solid electrolyte for ammonia sensors, as well as gas separation membranes.

The aim of this work is to study the ion transport in polymer electrolyte based on Nafion in the ammonium form plasticized by DMSO with the help of impedance spectroscopy. Experimental and theoretical studies of intermolecular interactions, phase and relaxation transitions, as well as morphology of the membranes were carried out by IR spectroscopy, differential scanning calorimetry, small-angle X-ray scattering, membrane swelling and quantum-chemical modeling.

\section{Experimental}

Membranes preparation.-The initial membrane Nafion-115 was preliminarly treated with $3 \%$ hydrogen peroxide solution at $80-100^{\circ} \mathrm{C}$ for 2 hours, washed with water, immersed in $1 \mathrm{M} \mathrm{H}_{2} \mathrm{SO}_{4}$ at $80-100^{\circ} \mathrm{C}$ for 2 hours, and finally washed with water. Mobile protons were replaced by ammonium cations by aging the samples in an ammonia aqueous solution (10\%) at $50-55^{\circ} \mathrm{C}$ for 2 hours, followed by thorough washing with water. To remove water, the samples were first dried at 


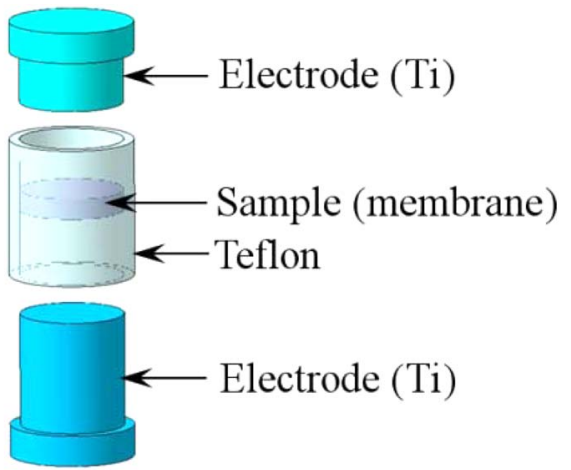

(a)

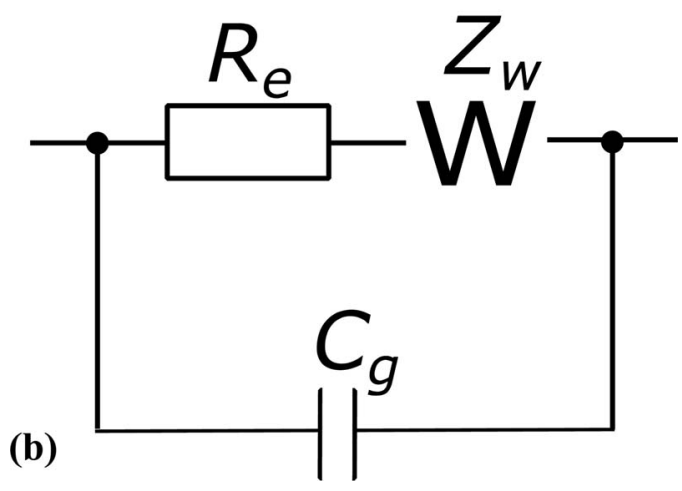

Figure 1. Scheme of measuring cell (a) and equivalent circuit of the impedance spectra (b): $R_{e}$ is the sample(electrolyte) resistance, $C_{g}$ is the geometrical capacitanceof the measuring cell, $Z_{W}$ is Warburg element.

$50^{\circ} \mathrm{C}$ for 3 hours in Büchi glass oven under vacuum of 10-15 mBar, and then were kept in the desiccator over $\mathrm{P}_{2} \mathrm{O}_{5}$ for a week.

To obtain swollen samples, the dried samples of Nafion in the $\mathrm{NH}_{4}{ }^{+}$ form were aged in the anhydrous DMSO (Aldrich) in the presence of activated molecular sieves for 2 days at room temperature. To receive the samples with less content of DMSO, the dried samples were placed shortly in the anhydrous DMSO, sponged with filter paper and held for two days for a uniform distribution of the plasticizer in the sample. DMSO content in the membrane $(W)$ in a solvent was defined according to Eq. 1.

$$
\mathrm{W}=\frac{\mathrm{m}_{\text {swoll }}-\mathrm{m}_{\text {dry }}}{\mathrm{m}_{\text {dry }}} \cdot 100 \%,
$$

where $m_{\text {swoll }}$ and $m_{d r y}$ are the weight of swollen and dry membranes, respectively.

The number of DMSO molecules per ammonium cation $(n)$ was calculated from the obtained values of $W$ according to Eq. 2 .

$$
\mathrm{n}=\frac{\mathrm{W} \cdot \mathrm{EW}}{\mathrm{Mr}_{\mathrm{DMSO}} \cdot 100 \%},
$$

where $\mathrm{EW}$ is equivalent weight of Nafion- $\mathrm{NH}_{4}$ equal to $1117, M r_{D M S O}$ is the molar mass of DMSO.

All the experiments with the polymer electrolyte were carried out in a dry box in argon atmosphere, the $\mathrm{O}_{2}$ and $\mathrm{H}_{2} \mathrm{O}$ contents were less than $1 \mathrm{ppm}$.

The water content in the used DMSO determined by coulometric Karl Fischer titration was less than 100 ppm. The residual water content in the swollen membranes did not exceed 0.1 molecules per sulfonic site.

Conductivity of the samples was measured by impedance spectroscopy. The experiments were performed using the Z-3000 instrument ("Elins" LLC) in the frequency range of $10 \mathrm{~Hz}-500 \mathrm{kHz}$ on symmetric cells Ti/Nafion- $\mathrm{NH}_{4} / \mathrm{Ti}$ with an active area of $0.2 \mathrm{~cm}^{2}$ in transverse direction of the membrane (Figure 1a). The preparation of the electrodes and assembly of the measuring cells was carried out in a dry box under argon atmosphere. Prior to the assembly of the cell, the electrodes were cleaned by mechanical polishing followed by washing with DMSO to avoid the formation of an oxide film on the surface of the titanium electrodes. The tightness of the cells prevents the penetration of water and the evaporation of DMSO during measurements. The amplitude of the external variable signal was ranging between 20 and $100 \mathrm{mV}$. To calculate the ion conductivity, the spectra of the experimental cell were approximated according to the equivalent circuit (Figure 1b). The simple equivalent circuit proved to be optimal for determination of the membrane's resistance. The bulk ion conduction corresponds to the resistor $R_{e}$ in the equivalent circuit. In the calculations, the geometrical capacitance of the measuring cell and connecting leads $\left(C_{g}\right)$ was accounted for, which is noticeable when large resistances are measured.

The specific conductivity of the membranes $\sigma$ was calculated from the ratio:

$$
\sigma=\frac{d}{R_{e} S}
$$

where $d$ is the thickness of the sample, $R_{e}$ is the sample resistance, $S$ is the area of electrical contact. The general error in determining the conductivity by impedance spectroscopy is about $10 \%$.

ATR IR spectra of the prepared samples were recorded under vacuum $(<1 \mathrm{hPa})$ on a Vertex $70 \mathrm{~V}$ spectrometer at room temperature using a Bruker diamond attachment in the $50-4500 \mathrm{~cm}^{-1}$ (resolution $4 \mathrm{~cm}^{-1}, 50$ scans). The spectra were presented in ATR units. At this scale, the spectra are normalized by the fixed depth of light penetration into the sample, thus ATR spectra in the distant IR region up to $50 \mathrm{~cm}^{-1}$ inclusive may be studied.

Small-angle X-ray scattering (SAXS) experiments were performed on the ID 02 beamline at the European Synchrotron Radiation Facility (Grenoble, France). The scattering patterns were collected with a FreLon $2 \mathrm{k}$ detector using the sample-to-detector distance of $1.5 \mathrm{~m}$. The wavelength used was $1.0 \AA$. The samples were sealed in kapton envelopes to prevent solvent evaporation. The modulus of the scattering vector was calibrated using several diffraction orders of silver behenate. One-dimensional curves were calculated by azimuthal integration of the 2D X-ray patterns corrected for incident beam intensity and absorption.

The thermal stability of the membranes was studied by thermogravimetric analysis (TGA) on the STA 409PC Luxx instrument (NET$\mathrm{ZSH}$, Germany) in alundum crucibles under the argon atmosphere. The heating rate was 10 degrees per minute. Phase transitions in the negative area were studied by differential scanning calorimetry (DSC) on a Mettler Toledo DSC 822e/200. The sample were placed in sealed aluminum crucibles, kept at the temperature of $-70^{\circ} \mathrm{C}$ for $5 \mathrm{~min}$, then heated up to $+20^{\circ} \mathrm{C}$ and cooled again at a rate of 10 degrees per minute. The mass fraction of freezing DMSO $\left(\omega_{F}\right)$ was determined from Eq. 4 without considering the thermal effect of solvation and ion association processes:

$$
\omega_{F}=\frac{\Delta H_{\text {exp }}}{\Delta H_{\text {calc }}} \cdot 100 \%,
$$

where $\Delta H_{\text {exp }}$ and $\Delta H_{\text {calc }}$ are the experimental and theoretical enthalpy of fusion of pure DMSO at the temperatute of phase transition $\left(T_{p h}\right)$.

The well-known Eq. 5 was used for calculating $\Delta H_{\text {calc }}::^{45}$

$$
\Delta H_{\text {calc }}=183.9+0.4431 \Delta T-1.991 \cdot 10^{-3} \Delta T^{2},
$$

where $\Delta T=18.55-T_{p h}$.

Quantum-chemical modeling was carried out in the framework of the B3LYP hybrid density functional ${ }^{46,47}$ and the $6-31 \mathrm{G}^{*}$ basis set by means of the GAUSSIAN program package. ${ }^{48}$

\section{Results}

Membrane swelling.-The DMSO uptake of the membrane at room temperature achieves up to $119.1 \mathrm{wt} \%$, which corresponds to 17.1 DMSO molecules per ammonium ion. This value is almost twice as high as that of the membranes in the $\mathrm{Na}^{+}, \mathrm{K}^{+}, \mathrm{Rb}^{+}$and $\mathrm{Cs}^{+}$forms 


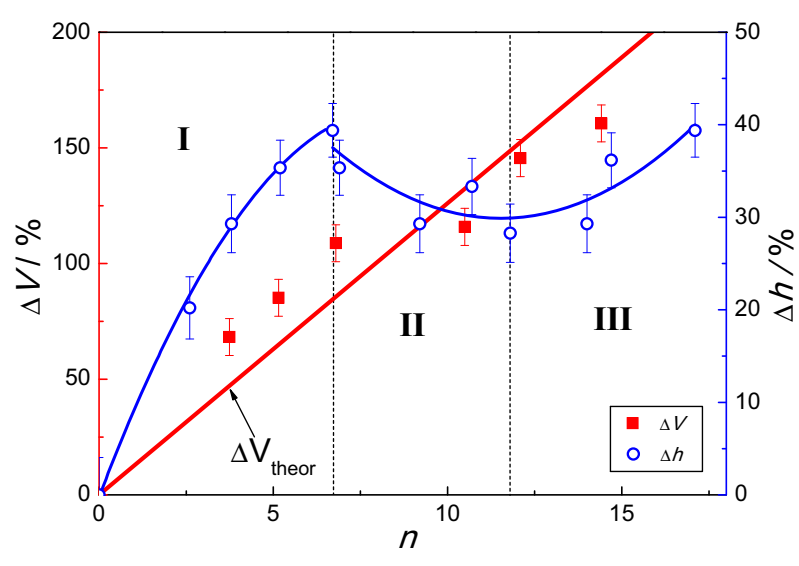

Figure 2. Relative change in the volume and thickness of the samples as a function of the DMSO content. The red line stands for the theoretical change in the volume.

and approaches that of the lithium form of Nafion $(\sim 130 \mathrm{wt} \%, n=$ 18.5). ${ }^{41}$ The spatial dimensions of the Nafion- $\mathrm{NH}_{4}$ membrane evolve unevenly with the increase in the DMSO content (Figure 2). When $n$ equals 6.5 the relative change in thickness $(\Delta h)$ and lateral dimensions is 40 and $25 \%$, respectively. The swelling anisotropy of the membranes can be attributed to the ionomer in-plane alignment due to extrusion process of the Nafion precursor as was revealed early by geometrical ${ }^{49}$ and SAXS ${ }^{50,51}$ study. 2D SAXS patterns of the films in this work measured in transmission show uniform orientation of the chains in the film plane. Also, for small $n$-values the change in the membrane volume $(\Delta V)$ is about $20 \%$ higher than the theoretical value, calculated as a sum of the volumes of the DMSO and the membrane. This indicates an increase of the free volume in the hydrophobic perfluorinated part of the polymer, probably as a result of the building up of mechanical stresses with a sharp increase in the volume of hydrophilic clusters during solvation. These assumptions are in good agreement with the positron spectroscopy data on the free volume increase in
Nafion membranes upon swelling in water and alcohol. ${ }^{52}$ Due to the capillary effect, the saturation of solvate shells and strong mechanical stresses with increasing $n$ leads to the diffusion of DMSO into the perfluorinated matrix and its plasticization accompanied by polymer relaxation. This is confirmed by experimental data on the change in the membrane volume at a high DMSO content $(n>10-12)$, when the volume of the swollen membrane even turns out to be slightly lower than the theoretical one. The latter indicates that DMSO molecules fill the free volume in the polymer that is present in the initial Nafion membrane, and, according to various estimates, this volume is one percent. $^{52,53}$

IR spectroscopy.-In the ATR FTIR spectrum of the unsolvated $\mathrm{NH}_{4}{ }^{+}$ion in Nafion, the $\nu_{3}$ band displays a complex shape (Figure 3). The main maximum is found at $3210 \pm 4 \mathrm{~cm}^{-1}$. The peak at $3079 \pm$ $2 \mathrm{~cm}^{-1}$ is about twice less intense. The maxima at $2925 \pm 5 \mathrm{~cm}^{-1}$ and $2862 \pm 10 \mathrm{~cm}^{-1}$ have a minimum intensity. In the liquid-phase spectrum of DMSO, the $v(\mathrm{SO})$ band is located at $1043 \mathrm{~cm}^{-1}$. The $\nu_{3}$ band refers to the triply degenerate stretching vibration of $\mathrm{NH}$. Its splitting is explained by the Fermi resonance between the fundamental vibration $v_{3}$, the combination vibration $v_{2}+v_{4}$, and the overtone $2 v_{4}$. There are no clear signs of a decrease in the tetrahedral symmetry of $\mathrm{NH}_{4}{ }^{+}$, although the symmetry would have to decrease due to the formation of a hydrogen bond with the sulfonic group $-\mathrm{SO}_{3}$.

Solvation of the ammonium ion by the DMSO molecules lowers the frequency of the valence vibration $\nu_{3}$ by more than $26 \mathrm{~cm}^{-1}$ and simultaneously increases the frequency of the deformation vibration $\nu_{4}$ by $29 \mathrm{~cm}^{-1}$. In addition, a decrease in the frequency of the stretching vibration of the DMSO molecule $\nu(S O)$ by $18 \mathrm{~cm}^{-1}$ is observed. These changes indicate that the DMSO molecule connected to the $\mathrm{NH}_{4}{ }^{+}$ion through a weak hydrogen bond N-H...O. Along with the plasticizer molecules attached to the ammonium ion, the DMSO molecules remain self-associative inside the polymer matrix, similar to the liquid DMSO. This is supported by the weak wide band of dipole-dipole interactions at $80 \mathrm{~cm}^{-1}$. This behavior of the plasticizer in Nafion is also typical for other cationic forms, ${ }^{41,54}$ except for the acidic form, in which the proton forms a strong complex with two molecules of DMSO. ${ }^{55}$ The absence of such complexes in the

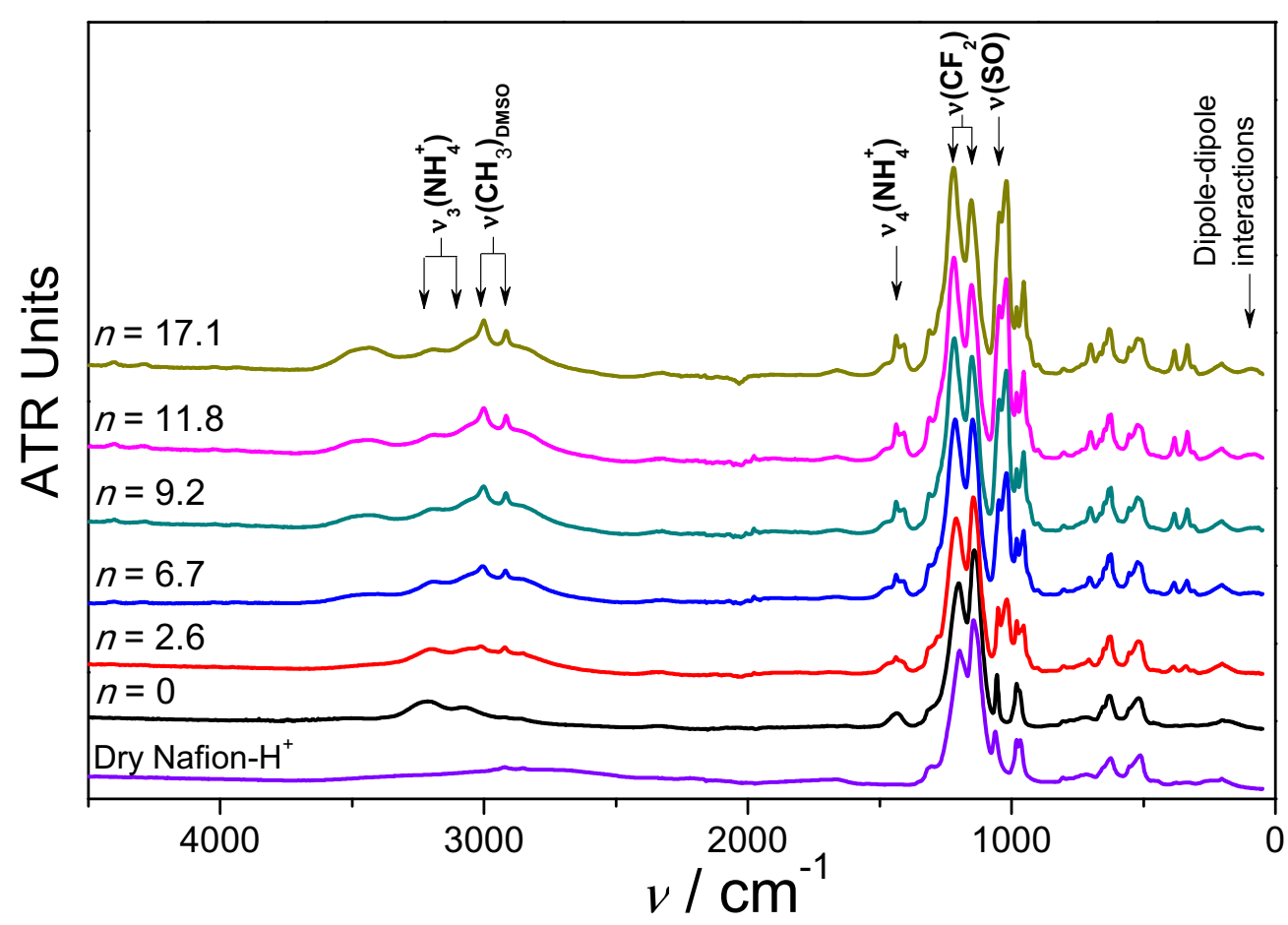

Figure 3. ATR FTIR spectra of the samples with different $n$-values. 


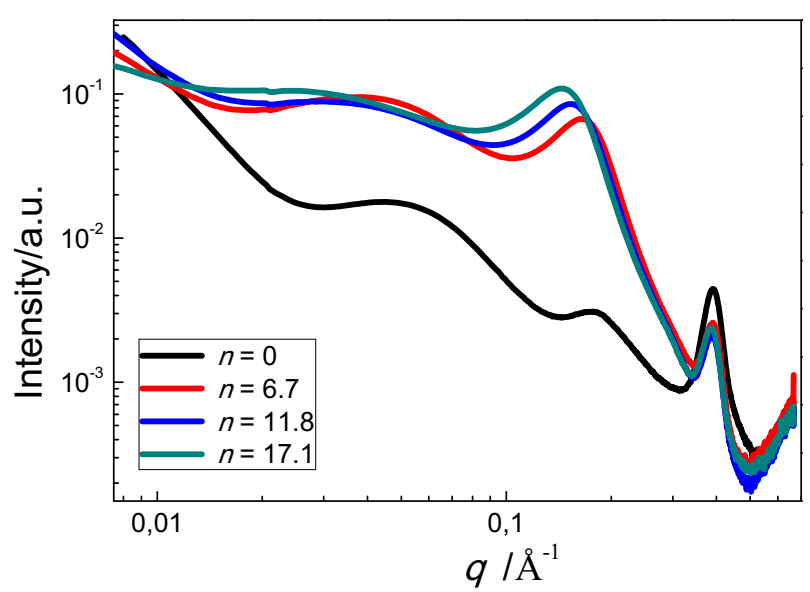

Figure 4. SAXS curves of the samples at different degrees of swelling in DMSO.

studied polymer confirms the absence of $\mathrm{H}^{+}$and full replacing of mobile protons by ammonium cations. A detailed study of $\mathrm{NH}_{4}^{+} \cdot n$ DMSO and $\mathrm{NH}_{4}{ }^{+} \cdot n$ DMSO-d6 solvates in Nafion by ATR FTIR and FTIR absorption spectroscopy is presented in work. ${ }^{56}$

SAXS.-The SAXS curves of all the studied films exhibit two characteristic peaks (Figure 4). A weak peak at the $q$ value of $0.38 \AA^{-1}$ stems from scattering from kapton envelope and therefore extraneous to the sample. The most intense maximum located within the $q$-range of $0.15-0.20 \AA^{-1}$ is typical of the Nafion-type materials. In contrast, a maximum at $0.03-0.05 \AA^{-1}$ reflects the semicrystalline organization of Nafion. ${ }^{57,58}$ In the following of paper, the latter peak will be termed supramolecular.

One can see from the Figure 5 that with addition of DMSO the intensity of the ionomeric peak noticeably increases with addition of solvent and then continues to grow at a smaller pace. In contrast, the intensity of the supramolecular peak reaches maximum at $n=6.7$ and decreases upon further addition of DMSO. The increase of the $d$ spacing of the main Nafion peak from 32 to $41 \AA$ reflects the increase of the ion-conductive channels' diameter approximately by ca. $30 \%$. At the same time, the increase of the small-angle distance is more pronounced, i.e. from 120 to $210 \AA$.

It is logical to suggest that the supramolecular peak is related to periodic alternation of ordered domains containing regular ion channels and disordered amorphous regions of a different electron density. On the basis of simple geometrical considerations one can estimate the relative change of the ordered domain size $\left(L_{c}\right)$ and distance between them $\left(L_{a}\right)$. Thus, for isotropic domains, their size is simply proportional to $d$-spacing: $L_{c}=k \cdot d$. The long period $L$ characterizes periodic arrangement of the ordered and amorphous domains: $L=L_{c}+L_{a}$. Therefore, one obtains:

$$
L_{a}=L-\left(L_{0}-L_{a 0}\right) \cdot\left(\frac{d}{d_{0}}\right)=L-\left(L_{0}-L_{a 0}\right) \cdot\left(\frac{L_{c}}{L_{c 0}}\right),
$$

where $L_{0}, L_{a 0}, L_{c 0}$ and $d_{0}$ are the corresponding parameters of the dry sample.

The long period and the size amorphous region are linked as: $L_{a 0}=w \cdot L_{0}$, where $w$ is the volume fraction of the amorphous phase. Consequently, the relative change of the amorphous region size can be estimated accordingly:

$$
\frac{L_{a}}{L_{a 0}}=\frac{1}{w} \cdot \frac{L}{L_{0}}-\frac{1-w}{w} \cdot \frac{d}{d_{0}}=\frac{1}{w} \cdot \frac{L}{L_{0}}-\frac{1-w}{w} \cdot \frac{L_{c}}{L_{c 0}} .
$$

Importantly, this estimation is irrespective of the particular shape of the channels (e.g., spherical or cylindrical) and requires only the condition of isotropic swelling. It has to be emphasized that our analysis is valid irrespectively of the hydrophilic domains morphology, which is still a matter of debate. ${ }^{59}$
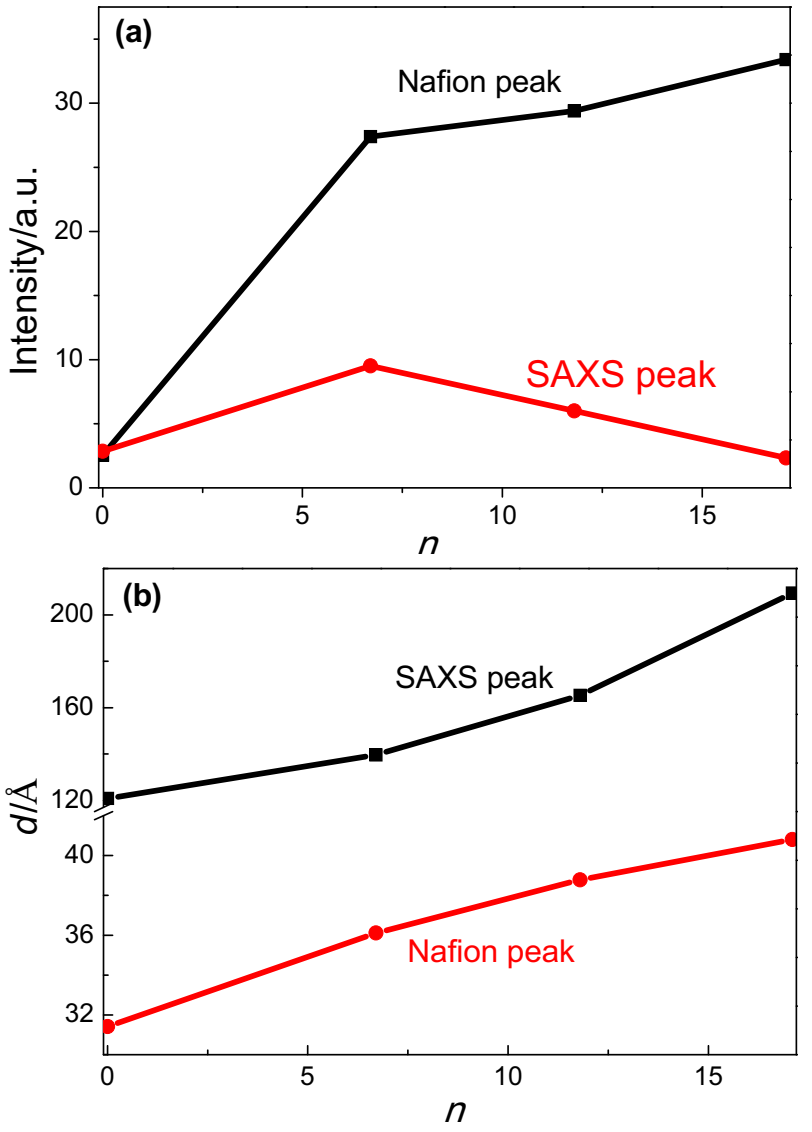

Figure 5. The supramolecular peak and Nafion peak intensity (a) and $d$ spacing (b) as a function of the DMSO content.

Taking into account the distance between the centers of channels of $3.1 \mathrm{~nm}$ and $L_{0}=12.1 \mathrm{~nm}$, one expects that the value of $w$ is in the range from 0.3 to 0.5 . The relative sizes of the ordered and amorphous domains as a function of $\mathrm{n}$ for $w=0.5$ are presented in Figure 6. One can see that for $n=6.7$ these values coincide. With increase of $n$, a very large increase of the amorphous domain size was detected that is related to intense swelling of the hydrophobic perfluorinatedNafion matrix. The decrease of supramolecular peak intensity at $n>6.7$ can be explained by a decrease of the electron density contrast due to impregnation of the polymer matrix by DMSO.

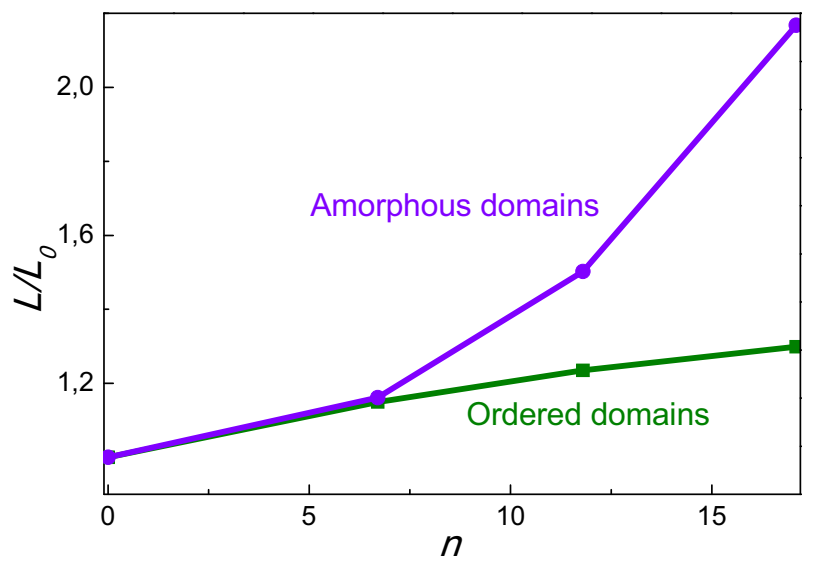

Figure 6. Relative size of the ordered and amorphous regions as a function of $n(w=0.5)$. 


\begin{abstract}
Table I. DMSO content obtained from gravimetry and TGA data $(W)$, ion conductivity at $30^{\circ} \mathrm{C}\left(\sigma^{30^{\circ}} \mathrm{C}\right)$ and activation energy of conductivity $\left(E_{a}\right)$ of studied electrolyte based on Nafion and DMSO.
\end{abstract}

\begin{tabular}{|c|c|c|c|c|c|c|}
\hline \multirow[b]{2}{*}{$n$} & \multirow[b]{2}{*}{$\sigma^{30^{\circ} \mathrm{C}}, \mathrm{S} \mathrm{cm}^{-1}$} & \multicolumn{2}{|c|}{$E_{a}, \mathrm{eV}$} & \multirow[b]{2}{*}{$W$, wt $\%$} & \multirow[b]{2}{*}{$W$ (TGA), wt $\%$} & \multirow[b]{2}{*}{$\Delta n$} \\
\hline & & Before $T_{p h}$ & After $T_{p h}$ & & & \\
\hline 0.0 & $1.1 \cdot 10^{-7}$ & 0.76 & - & 0 & - & - \\
\hline 2.6 & $1.4 \cdot 10^{-4}$ & 0.43 & - & 18.3 & - & - \\
\hline 6.7 & $2.7 \cdot 10^{-3}$ & 0.11 & 0.26 & 46.5 & 30.2 & 1.2 \\
\hline 9.2 & $2.7 \cdot 10^{-3}$ & 0.10 & 0.28 & 64.1 & 50.6 & 0.8 \\
\hline 11.8 & $3.7 \cdot 10^{-3}$ & 0.09 & 0.32 & 82.5 & 59.0 & 1.1 \\
\hline 14.0 & $4.0 \cdot 10^{-3}$ & 0.14 & 0.25 & 97.5 & 64.3 & 1.4 \\
\hline 17.1 & $4.2 \cdot 10^{-3}$ & 0.12 & 0.28 & 119.1 & 90.8 & 1.0 \\
\hline
\end{tabular}

TGA and DSC.-To study the effect of temperature on the transport properties of the ammonium form of Nafion, the thermal stability of the samples was studied for temperatures below and above room temperature.

The content of plasticizer in membranes obtained from TGA data is smaller than that obtained from the membrane weighing (Table I). On the average, the difference corresponds, on the average, to one DMSO molecule per ammonium ion, which is strongly bounded with the cation. The process of DMSO removal from the membrane in the flow of argon begins already at room temperature and continues to $200^{\circ} \mathrm{C}$ (Figure 7). A thermal decomposition of the polymer membrane was detected above $350^{\circ} \mathrm{C}$.

Phase transitions in the studied polymer electrolyte were investigated with DSC. For membranes with a low swelling degree ( $n$ $=0$ and 2.6), no thermal effects are observed on the DSC curves (Figure 8). The first barely noticeable endothermic peak is observed at $n=6.7$ with a maximum at $T_{p h}=-4.7^{\circ} \mathrm{C}$. Assuming that the total thermal effect of the solvation and ion association processes at $n$ $>6$ is negligible, the observed peaks were attributed exclusively to the melting/crystallization of DMSO. While the DMSO content increases, the peak maxima are shifted to the higher temperature region, approaching the melting point of pure DMSO. It is worth note, that the peak of $n=9.2$ is out of the observed dependence. Despite the lower DMSO content, their melting is observed at a higher temperature than that for sample of $n=11.8$. A non-contradictory explanation will be presented below. For a fully saturated sample $(n=17.1)$, an additional exothermic peak with a maximum at $+3.6^{\circ} \mathrm{C}$ is observed on the heating curve (after abrupt cooling down to $-70^{\circ} \mathrm{C}$ ). This peak disappears when the sample was previously isothermally held at this temperature, followed by cooling and reheating. Therefore, its presence is probably related to crystallization of supercooled DMSO above the glass tran-

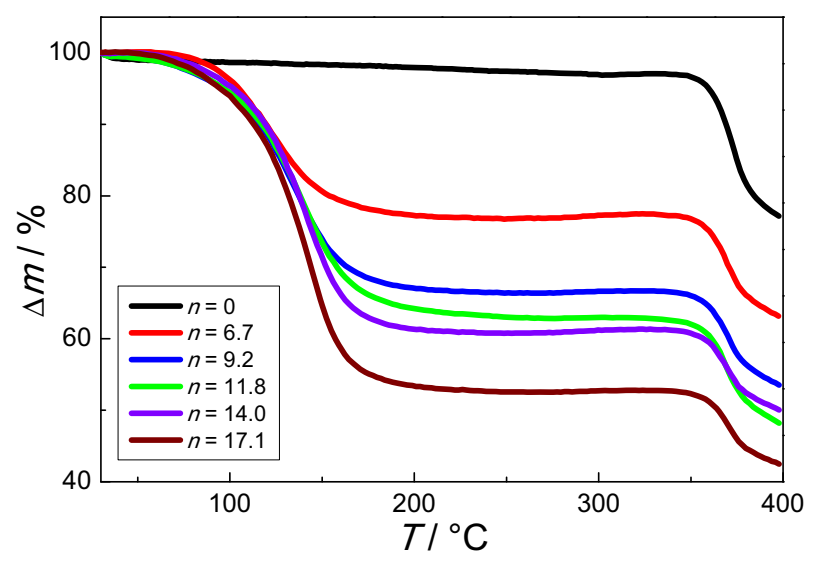

Figure 7. TGA curves of the electrolytes in the high temperature region. sition. The same phenomenon was observed for the lithiated Nafion saturated with DMSO. ${ }^{41}$

The values of the melting/crystallization enthalpy upon heating and cooling increase with $n$, reaching for $n=17.1$ the values of 96.2 and $107.4 \mathrm{~J} \mathrm{~g}^{-1}$, respectively (Table II). The calculated values of the enthalpy $\Delta H_{\text {calc }}$ (according to Eq. 5) are greater than the experimental onesfor all the compositions. Taking into account the absence of thermal effects for $n<6$, this effect can be associated with the presence of tightly bound and loosely bound solvent molecules, similar to those found for hydrated Nafion membrane.e. $\mathrm{g}^{60-63}$ The tightly bound DMSO is strongly associated with ions forming their first coordination sphere. The loosely bounded (bulk-like) DMSO molecules constitute the second and higher coordination spheres of the ions. The number of the second type molecules $\left(n_{F}\right)$ calculated from $\omega_{F}\left(n_{F}=n \cdot \omega_{F} / 100 \%\right)$ increases with $n$. The value of $n_{F}$ at the maximum saturation of the membrane reaches 8.9 and 9.7 upon heating and cooling, respectively (Table II). Intersection of the linear interpolation of $n_{F}$ values (blue line) with $\mathrm{x}$-axis gives the amount of non-freezing Nafion molecules per ammonium ion: $n_{N F}=6.9 \pm 0.9$ (Figure 9). Also, the number of non-freezing DMSO molecules can be determined as $n_{N F}=n-n_{F}=$ $7.4 \pm 0.8$ (red points and red line on Figure 9).

Quantum-chemical modeling.-Quantum-chemical modeling of intermolecular interactions responsible for ionic conductivity under conditions of high electrolyte concentration was carried out on a model system $\mathrm{NH}_{4}+/ n$ DMSO in the presence of a perfluorinated anion $\left(\mathrm{CF}_{3}\right)_{2} \mathrm{CFOCF}_{2} \mathrm{CF}_{2} \mathrm{SO}_{3}{ }^{-}$. At $n=1-3$, the ammonium ion is coordinated to the oxygen atoms of the $\mathrm{SO}_{3}$-group and to the plasticizer molecules. With addition of the fourth DMSO molecule, there are two possible configurations. In the first case, the previous configuration is retained, and the new molecule enters the second coordination sphere (4a1). In the second, all DMSO molecules are coordinated to ammonium (4b1), the $\mathrm{SO}_{3}$-fragment is slightly pushed aside, and the corresponding distance between the nitrogen and oxygen atoms of the sulfonic group $R(\mathrm{~N}-\mathrm{OS}$ ) increases from 2.8 to $3.1 \AA$ (Figure 10). The energy of second configuration is higher than that of the first one by $0.08 \mathrm{eV}$. For $n=5$ a similar situation was found, but the energy difference between configurations with different coordination numbers $(\mathrm{CN})$ of ammonium is even lower. At $n=6$, only one DMSO molecule is present into the second coordination sphere ( $\mathrm{CN}$ is equal to 6 ), $R(\mathrm{~N}-\mathrm{OS})=3.2 \AA$, and $R(\mathrm{~N}-\mathrm{S})=3.7 \AA$ (Figure $10,6 \mathbf{c 1}$ ). $\mathrm{A}$ further increase of the number of plasticizer molecules $(n=7,10,12$, 15) leads to formation of a "cocoon" encapsulated the ion pair, while the ammonium $\mathrm{CN}$ decreases to four, and the distance to the sulfonic group increases $(R(\mathrm{~N}-\mathrm{S})=4.0,4.4,5.2$ and $5.3 \AA$, respectively).

When the ammonium cation is removed from the Nafion sulfonic group, the corresponding potential energy depends significantly on the number of plasticizer molecules. For the configuration with $n=4$ in case $4 \mathbf{a}$, increasing the distance $R(\mathrm{~N}-\mathrm{S})$ leads to a rapid increase in the potential energy (Figures 10, 11). However, for $R(\mathrm{~N}-\mathrm{S}) \sim 5.5 \AA(\mathbf{4 a 2})$ the energy drastically drops because of the change of the cation environment (4a3). In structure $4 \mathrm{~b}$, ammonium is initially coordinated by four molecules of DMSO. Such coordination is less energy-efficient for $R(\mathrm{~N}-\mathrm{S})<4 \AA$ but its energy grows slower at higher distances than for the 4 a configuration. Both potential energy curves in the region of 6-7 $\AA$ are almost identical only when the cation environment changes (Figure 11). It is logical to assume that for $n<4$ the removal of the cation from the $\mathrm{SO}_{3}$-group is even more difficult. At $n=4$, the bond of the cation with the sulfonic group weakens, and its removal by a distance of $\sim 7 \AA$ leads to an increase in energy by $0.3 \mathrm{eV}$. While $n$ increases to 6 , the change in $R(\mathrm{~N}-\mathrm{S})$ in the range of 3.7-6.5 changes the energy by less than $0.1 \mathrm{eV}$. At $R(\mathrm{~N}-\mathrm{S}) \sim 6 \AA$ a second minimum appears and some DMSO molecules are incorporated between the solvated cation and sulfonic group (Figures 10,11). When $n$ increases to 12 , the potential energy curve becomes planar with two small minima. The ammonium is coordinated to the $\mathrm{SO}_{3}$-group and three DMSO molecules in the first minimum (12d1) or to four DMSO molecules in the second one $(\mathbf{1 2 d} 2)$. When the $R(\mathrm{~N}-\mathrm{S})$ increases to $9 \AA \mathbf{~ ( 1 2 d 3 )}$, the coordination of ammonium is unchanged, while the 

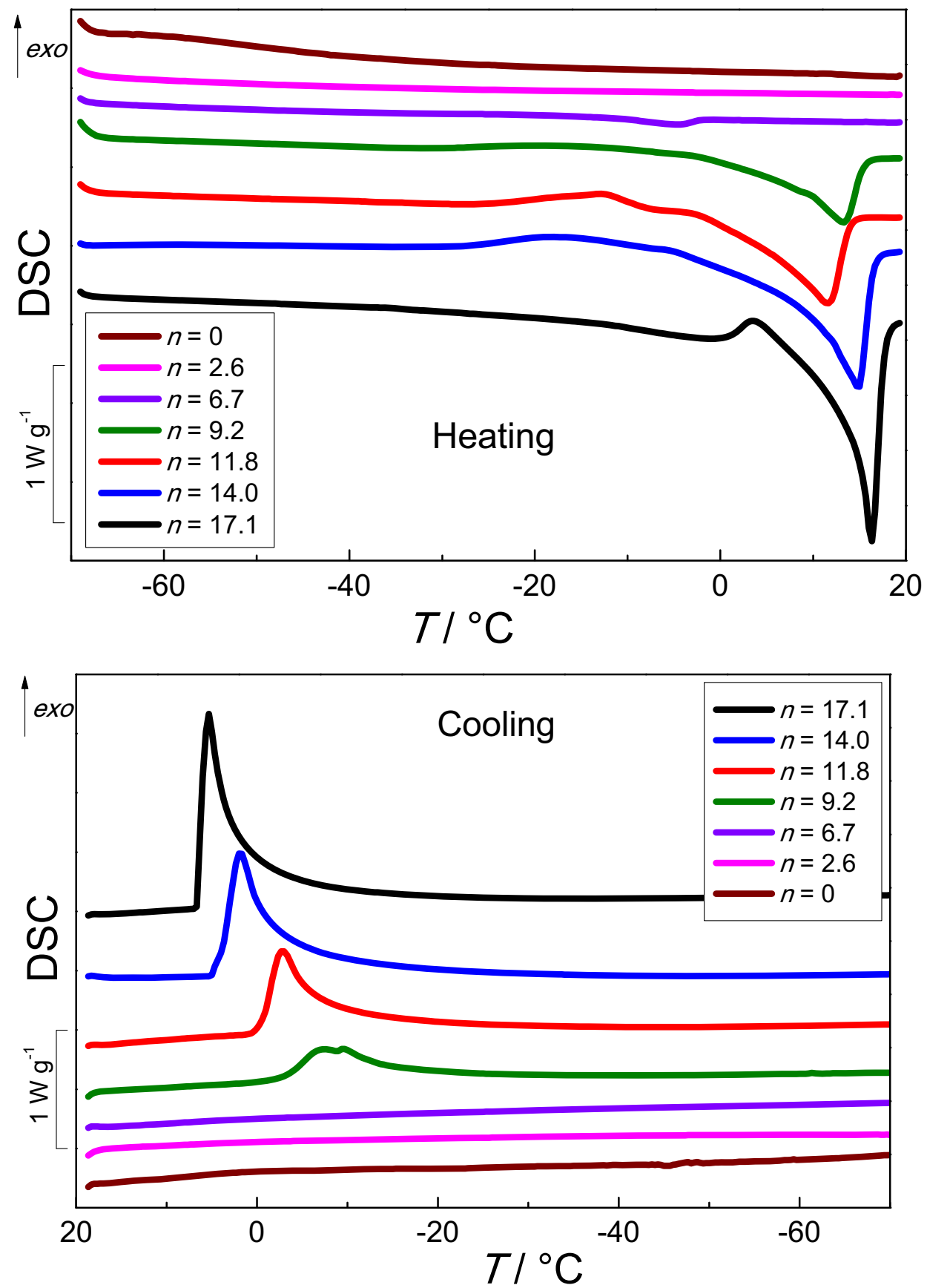

Figure 8. DSC curves in the low temperature region during heating and cooling.

\begin{tabular}{|c|c|c|c|c|c|c|c|c|c|c|}
\hline$n$ & \multicolumn{5}{|c|}{ Heating } & \multicolumn{5}{|c|}{ Cooling } \\
\hline 6.7 & -4.7 & 193.1 & 3.5 & 1.8 & 0.1 & - & - & - & - & - \\
\hline 9.2 & 13.2 & 186.2 & 46.0 & 24.7 & 2.3 & -8.6 & 194.5 & 47.1 & 24.2 & 2.2 \\
\hline 11.8 & 11.4 & 187.0 & 56.0 & 30.0 & 3.5 & -2.7 & 192.4 & 67.7 & 35.2 & 4.2 \\
\hline 17.1 & 16.1 & 185.0 & 96.2 & 52.0 & 8.9 & 5.6 & 189.3 & 107.4 & 56.7 & 9.7 \\
\hline
\end{tabular}

*The enthalpy values are given in J per gram of DMSO. $\Delta H_{0}$ is the enthalpy of fusion of pure DMSO $\left(\Delta H_{0}=183.9 \mathrm{~J} \mathrm{~g}^{-1}\right)$. 


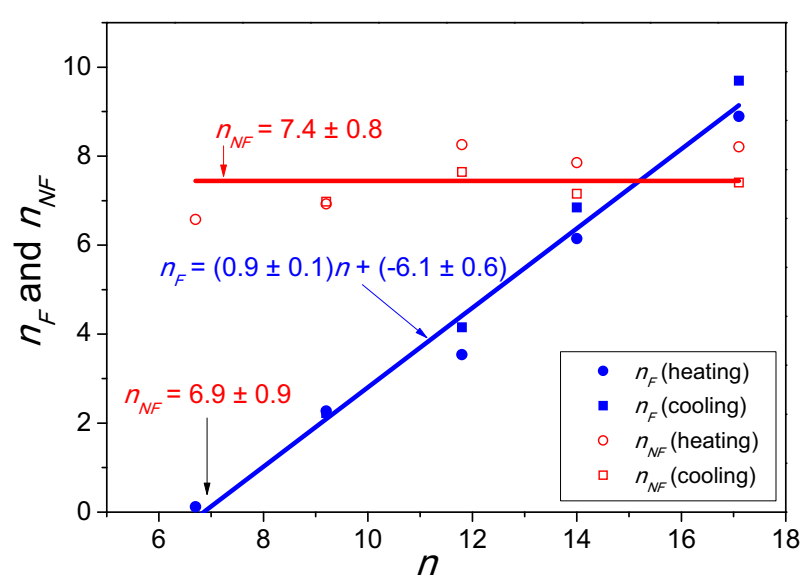

Figure 9. Dependences of the number of freezing $\left(n_{F}\right)$ and non-freezing $\left(n_{N F}\right)$ DMSO on $n$ calculated from heating and cooling segments of the DSC curves.

plasticizer molecules form a "cocoon" covering both the cation and anion (Figures 10, 11).

Thus, at a small number of DMSO molecules per sulfonic group (up to four), the anion and cation are tightly bound, and a significant energy costs are required for the conductivity activation. When $n$ increases to 6 , the cation can be easily moved from the $\mathrm{SO}_{3}$-group to a distance of $\sim 6-7 \AA$. With further growth of $n$, the energy barrier drops to $0.1 \mathrm{eV}$.

Impedance spectroscopy.-Typical Nyquist plots for the studied Nafion in ammonium form are shown in Figure 12. The Nyquist plot is a part of the semicircle followed by the "spur". The resulting impedance spectra are well approximated by the equivalent circuit shown in Figure 1. With increase of the temperature, a part of the semicircle disappears and only the "spur" remains. The swelling degree of the membrane does not affect the shape of the curves.

\section{Results and Discussion of Ionic Conductivity}

Features of the transport parameters of the Nafion$\mathrm{NH}_{4}{ }^{+}$membranes, plasticized by DMSO.-The temperature dependence of the ionic conductivity of the Nafion- $\mathrm{NH}_{4}$ membrane saturated by DMSO is shown in Figure 13. The measurement begins after quenching of the samples to $-70^{\circ} \mathrm{C}\left(\sim 10^{\circ} \mathrm{C} / \mathrm{min}\right)$. The exposure time in each point was determined by equilibration of the resistance, i.e. less than 5\% change in active resistance value ( $\left.Z^{\prime}\right)$ for 30 min duration. It is interesting to note that for subsequent heating-cooling cycles, the effect of the phase transition on the electric transport parameters is significantly reduced and only small kink is observed at $T_{p h}=+10^{\circ} \mathrm{C}$. Vitrification of DMSO in the membrane as a result of sharp cooling of
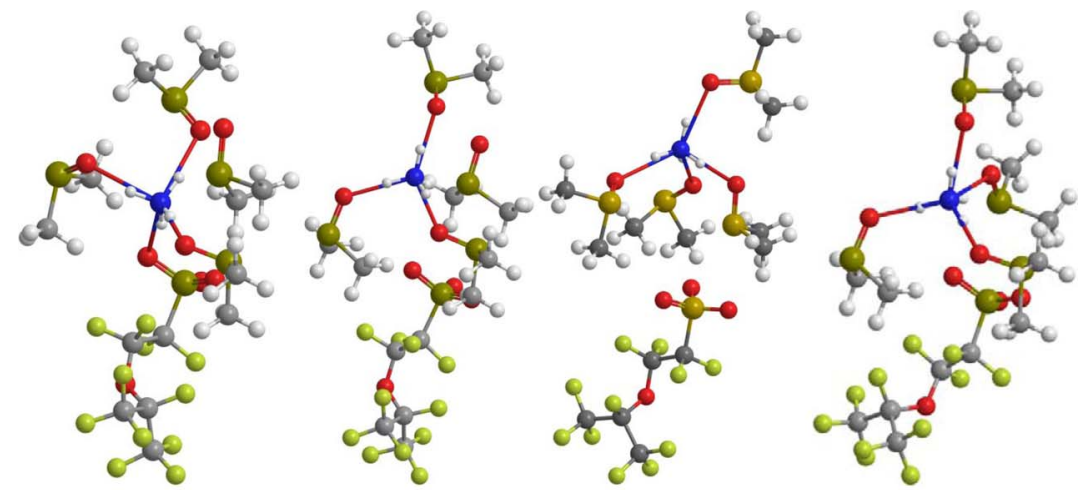

4a1,$R(\mathrm{~N}-\mathrm{S})=3.7 \AA ; \quad 4 \mathbf{a 2}, R(\mathrm{~N}-\mathrm{S})=5.5 \AA ; \quad 4 \mathbf{a 3}, R(\mathrm{~N}-\mathrm{S})=6 \AA ;$
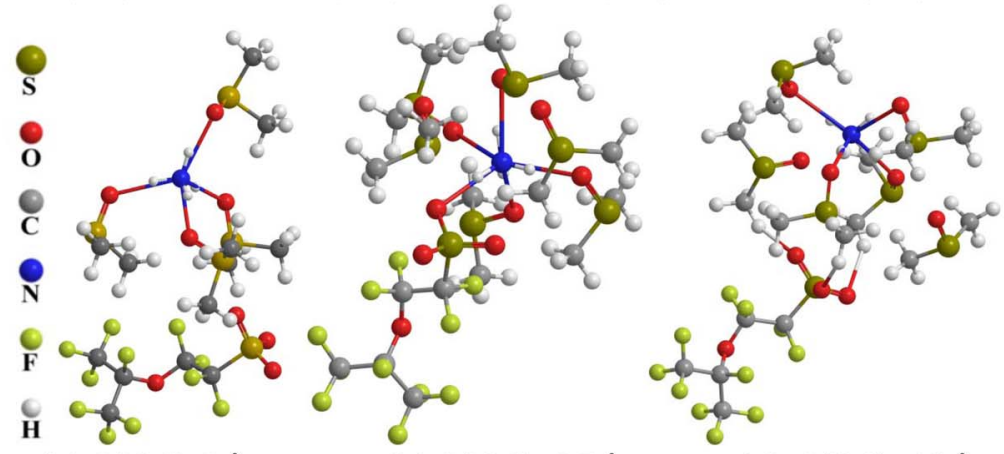

$4 \mathbf{b} 2, R(\mathrm{~N}-\mathrm{S})=7 \AA$

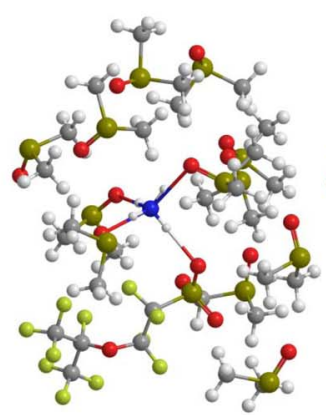

$12 \mathrm{~d} 1, R(\mathrm{~N}-\mathrm{S})=4.0 \AA$ 6c1, $R(\mathrm{~N}-\mathrm{S})=3.7 \AA$

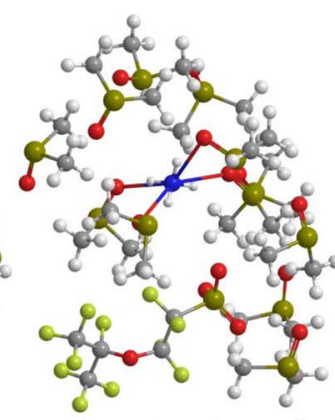

12d2, $R(\mathrm{~N}-\mathrm{S})=5.2 \AA$

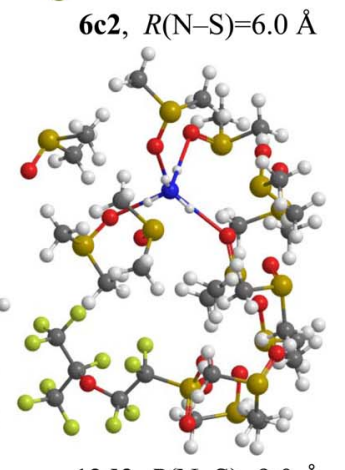

$12 \mathrm{~d} 3, R(\mathrm{~N}-\mathrm{S})=9.0 \AA$
Figure 10. Ammonium cation at different distances $(R)$ from the sulfonic acid group of Nafion surrounded by 4, 6 and 12 DMSO molecules. 


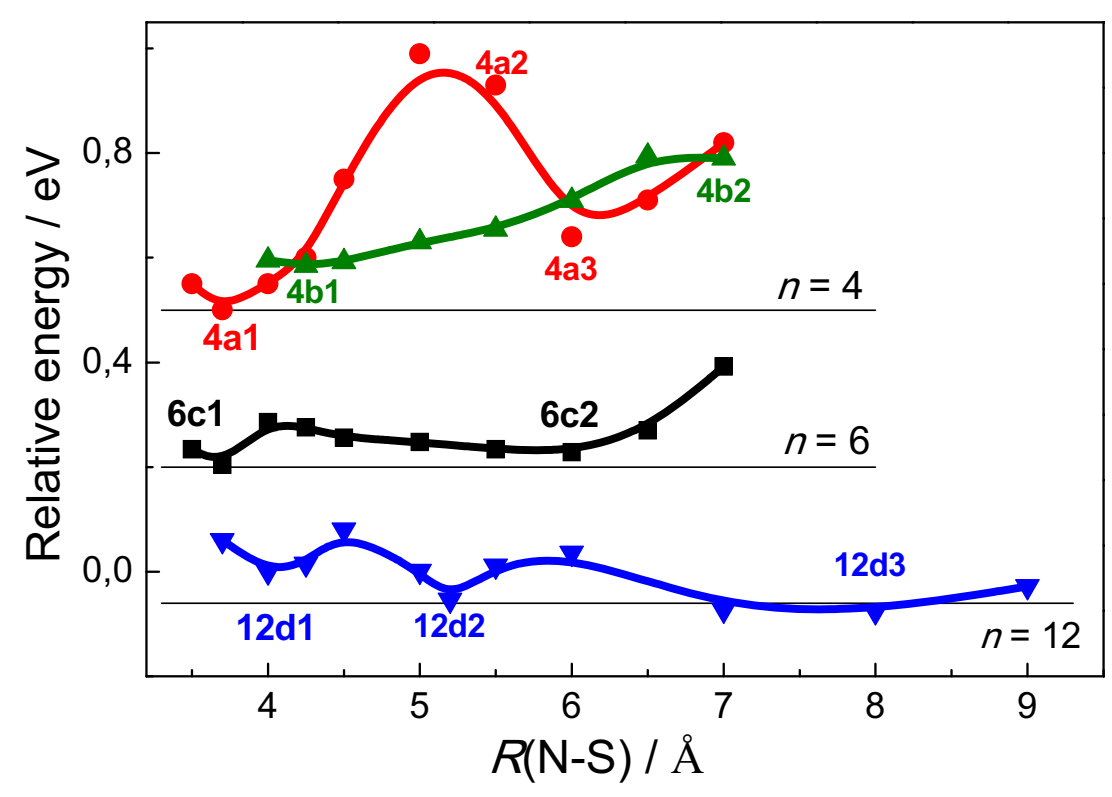

Figure 11. Potential energy curves of the ammonium ion removal from the sulfonic group with different amounts of DMSO molecules. Horizontal lines are zero levels for a given $n$. membrane samples is probably the reason for the appearance of a sharp jump-like behavior of the temperature dependence of the conductivity in the first cycle of measurements. All the temperature dependences presented below were obtained after 2-3 heating-cooling cycles.

It can be seen that the conductivity value, reaching $\sim 3-4 \mathrm{mS} \mathrm{cm}^{-1}$ at room temperature, is abnormally high and comparable to the conductivity of Nafion membranes in the $\mathrm{H}^{+}$and $\mathrm{Li}^{+}$forms. These results are in good agreement with other reports. ${ }^{27}$ To investigate the reasons of the high conductivity, the transport parameters of the membranes with different DMSO contents $(n)$ were studied in a wide temperature range. In the investigated temperature range from -80 to $+70^{\circ} \mathrm{C}$, all the ion conductivity dependences straight in the Arrhenius coordinates: $\sigma=\sigma_{0} \cdot \exp \left(-E_{a} / k T\right)$ (Figure 14). The values of the conductivity activation energy were calculated from the lines slope. At a low DMSO content ( $n=0$ and 2.6), there are no noticable inflections on the lines. The kink noted earlier is observed only for $n>6$, and its position (at $T_{p h}=+10^{\circ} \mathrm{C}$ ) is practically independent of $n$. These data are in good agreement with the DSC results, according to which the phase transitions are only observed for samples with $n>6$.

The dependences of the ionic conductivity $(\sigma)$ and the activation energy of conductivity $\left(E_{a}\right)$ of the samples on $n$ are shown in Figure 15. One can note the unusual behavior of transport parameters from the DMSO content and temperature.

First, three regions can be distinguished on the dependences of ionic conductivity (Figure $15 \mathrm{a}$ ). The first region $(n<6)$ is characterized by low conductivity $\left(10^{-7}-10^{-4} \mathrm{~S} \mathrm{~cm}^{-1}\right)$ and high $E_{a}(0.76$ and $0.43 \mathrm{eV}$ for $\mathrm{n}=0$ and 2.6 , respectively) values. In region II $(n=6-12)$, above $0^{\circ} \mathrm{C}$ the electrolyte has a high conductivity and low activation energy of conductivity $(\sim 0.1 \mathrm{eV})$. With an increase in the DMSO content, the conductivity appreciably increases and reaches $\sim 4 \mathrm{mS} \mathrm{cm}^{-1}$. In region III $(n \geq 12)$, the transport parameters are comparable to region II, but the conductivity is practically independent of the DMSO content.

Second, for all the investigated temperatures, at the boundary of the II and III regions an abrupt change in the activation energy is observed, as well as conductivity in the low-temperature region.

Third, in the low-temperature region, an anomalous behavior of the conductivity and the conductivity activation energy from the DMSO content is observed. In regions II and III, with an increase in $n, \sigma$ decreases noticeably ( $\sim 30-60 \%)$, and $E_{a}$ increases ( $\left.20 \%\right)$.

Transport properties at above phase transition temperatures.Low conductivity values and high values of the conductivity activation energy in region $\mathrm{I}(n<6)$ can be explained by two reasons, both being related to the small content of the plasticizer. The first reason is the phase separation between the hydrophilic clusters and perfluorinated matrix. In the membrane there are no or underdeveloped transport channels providing effective ion transport. It is known that for water containing Nafion in the $\mathrm{H}^{+}$-form the average water-volume fraction percolation threshold is close to $0.1^{64}$ which correspondsto the DMSO content $n \sim 8$. In the second case, the lack of DMSO leads to a strong coulomb interaction of the ammonium ion with the sulfonic group, which affects the concentration and mobility of the charge carriers. The strong ionic interactions in the system with low DMSO content are confirmed by the results of quantum-chemical modeling and DSC in the low-temperature region. According to the simulation of the $\mathrm{R}_{\mathrm{f}} \mathrm{SO}_{3}{ }^{-} \mathrm{NH}_{4}{ }^{+} / n$ DMSO system, for $n=4$ the removal of the cation from the $\mathrm{SO}_{3}$-group occurs with significant energy costs $(>0.4 \mathrm{eV})$, which are comparable to the experimental values of the conductivity activation energy. The boundary of the regions also agrees with the calculated data. The cation is weakly bound to the anion already for $n=6$. The change in $R(\mathrm{~N}-\mathrm{S})$ in the range 3.7-6.5 $\AA$ changes the energy by no more than $0.1 \mathrm{eV}$. Moreover, a second minimum appears at $R(\mathrm{~N}-\mathrm{S}) \sim 6 \AA$, where some DMSO molecules are built in between the solvated cation and the sulfonic group. The calculated data are in a good agreement with the results of a low-temperature DSC. According to the method, in the studied samples with about $50 \mathrm{wt} \%$ of DMSO $(n \sim 7)$ it does not undergo a phase transition, regardless of the DMSO content. Obviously, these DMSO molecules are firmly bound to ammonium ions. Due to the incomplete saturation of the solvation shell of the cation, for $n<6$ there is no phase transition in the samples.

Generally, the dependence of transport properties of the studied electrolyte in region II corresponds to the behavior of ion-conducting membranes. The first coordination sphere have been saturated $(n>$ 6), and the main percolation threshold is passed through. Thus, an increase in the DMSO content should lead to an increase in conductivity due to the development of the transport channels network and a decrease in the cation-anion interactions. The calculated ammonium ion migration barriers are in a good agreement with the experimental values of the conductivity activation energy $\left(E_{a} \sim 0.1 \mathrm{eV}\right)$. Surprisingly, despite the significant difference in cation sizes, the ionic conductivity of membranes in the $\mathrm{NH}_{4}{ }^{+}$-form is comparable to membranes in the $\mathrm{Li}^{+}$and $\mathrm{H}^{+}$forms and is about 5 times higher that $\sigma$ of the membrane in the $\mathrm{Rb}^{+}$-form $\left(1.43 \AA\left(\mathrm{NH}_{4}\right)-1.49 \AA(\mathrm{Rb})\right)$. Taking into account the high concentration of electrolyte $(\sim 1-2 \mathrm{M})$, it is obvious that the membrane conductivity is largely determined by the processes of ion association, mainly by the concentration of charge carriers. An increase in the concentration of ammonium ions relative to alkali metal ions with comparable radius can be ensured both by more effective solvation due to a less symmetrical structure and the formation of a 

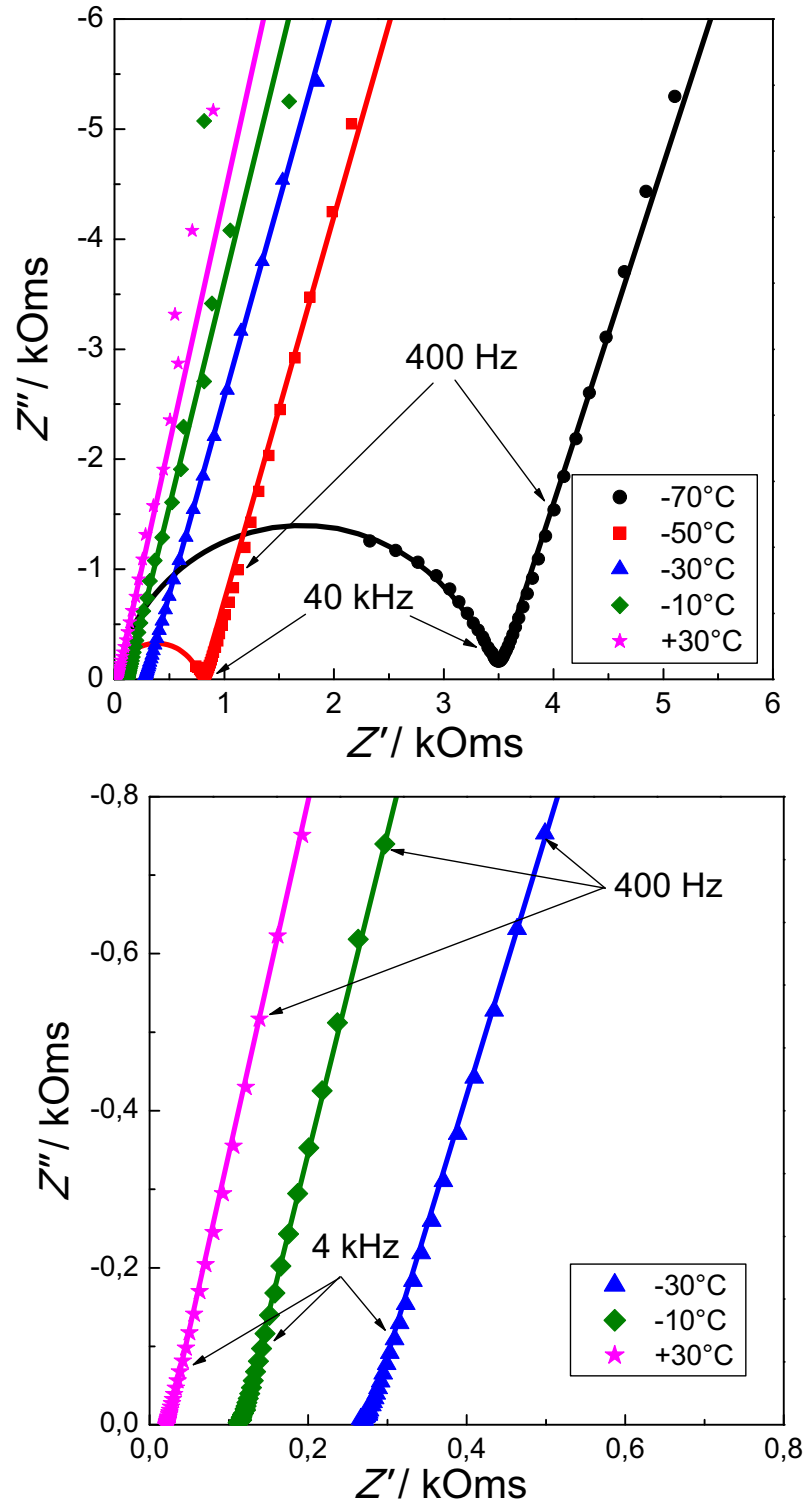

Figure 12. Nyquist plots for the ammonium form of Nafion $(n=6.7)$ at different temperatures: experimental (markers) and calculated from the equivalent circuit (lines).

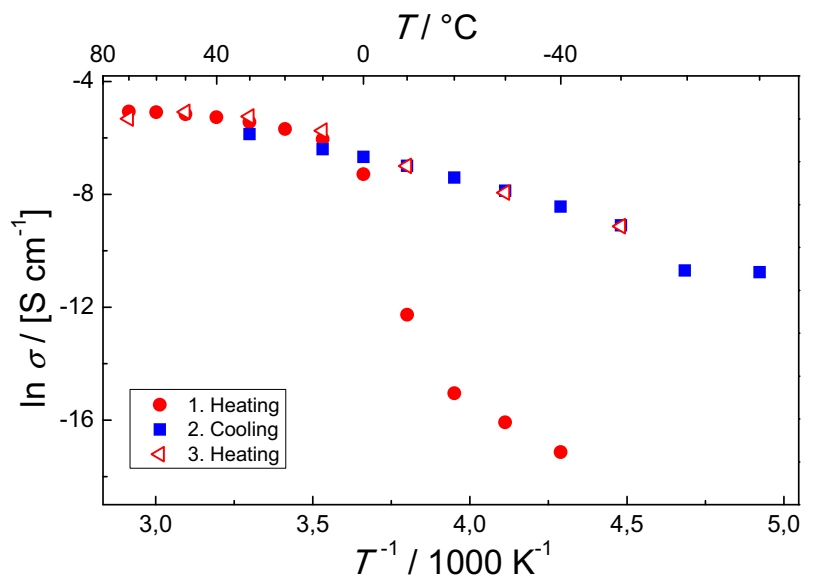

Figure 13. Temperature dependence of the membrane conductivity $(n=17.1)$.

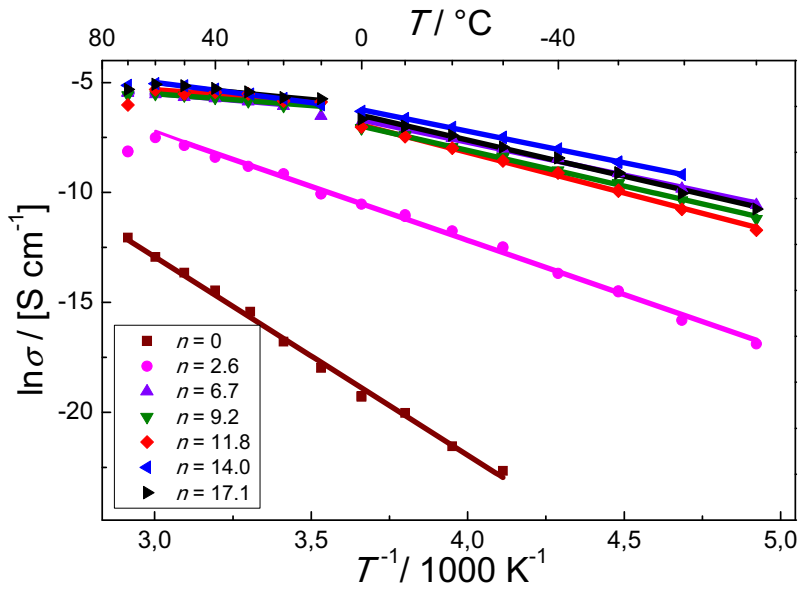

Figure 14. Temperature dependences of ionic conductivity of the samples under study.

hydrogen bond with DMSO, and due to weaker interaction with the anion. Thus, according to the data of the work, ${ }^{65}$ the free solvation energy of the ammonium ion by DMSO $\left(\Delta G_{S}\right)$ is by $2 \mathrm{kcal} \mathrm{mol}^{-1}$ greater than the solvation of the potassium ion, although the ammonium cation is much larger. In addition, the solvent uptake of the Nafion membrane in the $\mathrm{NH}_{4}{ }^{+}$-form, which largely depends on the relationship of the cation interaction energy with DMSO and with the anion, is $119.1 \mathrm{wt} \%$ $(n=17.1)$. This value is almost twice higher than for membranes in
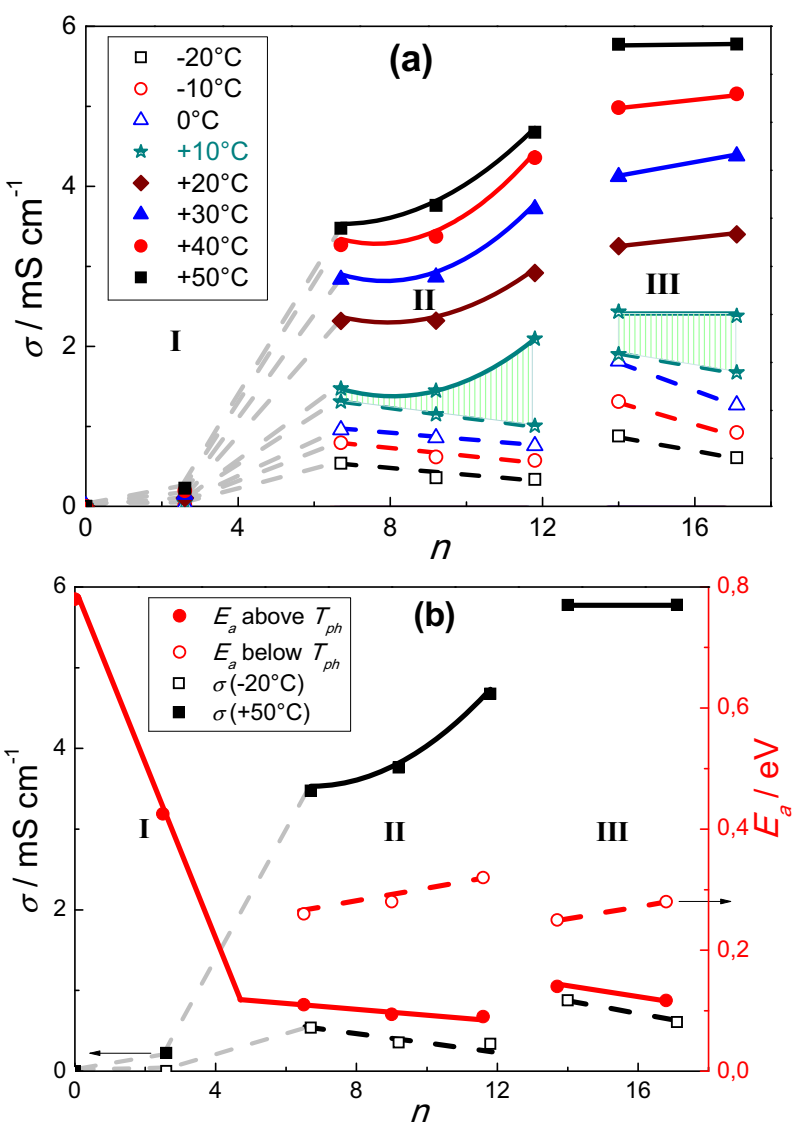

Figure 15. Dependences of ionic conductivity (a) and activation energy of conductivity (b)above and below the inflection point $T_{p h}$ on the DMSO content in ammonium Nafion. 
the $\mathrm{Na}^{+}, \mathrm{K}^{+}, \mathrm{Rb}^{+}$and $\mathrm{Cs}^{+}$-forms and approaches the lithiated form of Nafion $(\sim 130 \mathrm{wt} \%, n=18.5)$.

It is worth noting that according to the Figure 2 the experimental and calculated volumes become equal at $n \sim 9-10$. This means that either new portions of DMSO fill the free volume of the polymer matrix, or the polymer matrix relaxes followed by the collapse of these pores. The realization on the first way is likely process due to high enough solvent uptake membrane values causing the negligible gain from ion solvation and the appreciable matrix mechanical stresses. In this case a reasonable explanation of the melting of DMSO in the sample of $n=9.2$ at a higher temperature than that for a sample with a higher DMSO content $n=11.8$ (Figure 8) can be done. It is obviously that DMSO presented in the electrolyte-free pores (and, accordingly, does not participating in ion solvation) will melt at a higher temperature. Such DMSO adsorption by the pores also explains the negligible effect of $\sim 1$.4-fold increase in the DMSO content on ion conductivity. However, addition of new DMSO portions $(n=11.8$ and higher), probably due to the finishing the filling of the free polymer volume and plasticization of the perfluorinated matrix (reduction of mechanical stresses), leads to DMSO sorption by ionic groups with following evolution of the transport channels and reduction of the ion association. This explains the observed significant increase in ion conductivity at $n>9$.

The end of this process is achieved at $n=14$ (region III), above which the effect of the DMSO content on conductivity is insignificant. It is possible due to the compensation of the effect of increasing the mobility of charge carriers by reducing of their concentration due to dilution takes place. The observed increase in the conductivity activation energy at the boundary of the II and III regions can be associated with reorganization of transport channel and polymer matrix morphology due to the plasticization of the hydrophobic perfluorinated backbone and increase in the mobility of the polymer chains that constitute the channel framework. Further increase in the DMSO content leads to a saturation of the reconstructed transport channels and, accordingly, to a decrease in $E_{a}$.

The participation of DMSO in plasticizing of the hydrophobic matrix is confirmed by SAXS data. The latter allow suggesting that for $n>6$ an active swelling of the perfluorinated matrix in DMSO occurs. This leads to a strong increase in the amorphous domain sizes and to a decrease of the supramolecular peak intensity.

Transport properties at below phase transition temperatures.As can be seen from the obtained results, in the low-temperature region, i.e. in regions II and III the conductivity noticeably decreases (by ca. 30-60\%), and the conductivity activation energy $E_{a}$ increases ( $\sim 20 \%$ ) with increasing $n$. According to the DSC the decrease of transport properties with an increase in $n$ can be related to the increase in the amount of crystallizing DMSO. The formation of crystalline DMSO, in turn, can block the ion transport both by elongating the ion transport pathway and by narrowing of the transport channel. Moreover, at the maximum solvent uptake, formation of a dielectric layer at the membrane/electrode boundary is possible due to freezing of the plasticizer. That probably causes a considerable spread in the conductivity values at $T=+10^{\circ} \mathrm{C}$ (Figure 15 ).

It is interesting to note that, in contrast to the region of temperatures above $0^{\circ} \mathrm{C}$, an increase in the ion conductivity with a simultaneous decrease in the conductivity activation energy is observed below the phase transition at the boundary of regions II and III. It is possible that the observed behavior is caused by a decrease in the DMSO crystal particles inside the transport channels due to rearrangement of the polymer matrix at $n>10-12$.

\section{Conclusions}

The properties of electrotransport and thermophysical characteristics of Nafion-like ammonium-substituted polymeric membranes, plasticized by DMSO have been studied. A stepwise change in the ionic conductivity and conductivity activation energy of the membrane was observed for the first time as a function of the plasticizer content.
It was shown that strong solvation takes place up to $n \leq 6$, after which the ion transport is adruptly intensified. The change in conductivity for $n>9$ results from the swelling of the polymer matrix with a change in the morphology of the conducting channels, which is confirmed by the small-angle X-ray scattering data. The quantum-chemical modeling confirms that at a low DMSO content $(n \leq 4)$, cation removal from the $\mathrm{SO}_{3}$-group occurs with significant energy costs $(>0.4 \mathrm{eV})$. As the DMSO content increases, both the separation energy of the cation and the energy barriers to ammonium ion migration drastically decrease (to $0.1-0.2 \mathrm{eV}$ ). For $n>2.5$, the temperature and enthalpy of the phase transitions noticeably depend on the DMSO content.

\section{Acknowledgments}

All this work except of SAXS experiments was supported by Russian Scientific Foundation (Contract No. 17-79-30054). The authors acknowledge the Ministry of Science and High Education of the Russian Federation for financial support of SAXS experiments (contract No. 14.587.21.0052 (RFMEFI58718X0052)).

\section{ORCID}

Lyubov V. Shmygleva (D) https://orcid.org/0000-0001-5659-0634

\section{References}

1. A. Kraytsberg and Y. Ein-Eli, Energy Fuels, 28, 7303 (2014).

2. P. G. Bruce, B. Scrosati, and J.-M. Tarascon, Angew. Chem. Int. Edit., 47, 2930 (2008).

3. J. G. Kim, B. Son, S. Mukherjee, N. Schuppert, A. Bates, O. Kwon, M. J. Choi, H. Y. Chung, and S. Park, J. Power Sources, 282, 299 (2015).

4. D. Kundu, E. Talaie, V. Duffort, and L. F. Nazar, Angew.Chem. Int. Edit., 54, 3431 (2015).

5. P. Saha, M. K. Datta, O. I. Velikokhatnyi, A. Manivannan, D. Alman, and P. N. Kumta, Prog. Mater. Sci., 66, 1 (2014).

6. K. Xu, Chem. Rev., 104, 43030 (2004)

7. P. V. Wright, MRS Bull., 27, 597(2002).

8. D. T. Hallinan Jr. and N. P. Balsara, Annu. Rev. Mater. Res., 43, 503 (2013).

9. K. Xu, Chem. Rev., 114, 11503 (2014)

10. E. M. Erickson, E. Markevich, G. Salitra, D. Sharon, D. Hirshberg, E. Llave, I. Shterenberg, A. Rozenman, A. Frimer, and D. Aurbach, J. Electrochem. Soc., 162, A2424 (2015)

11. H. Zhang, C. Li, M. Piszcz, E. Coya, T. Rojo, L. M. Rodriguez-Martinez, M. Armand, and Z. Zhou, Chem. Soc. Rev., 46, 797 (2017).

12. A. Ponrouch, D. Monti, A. Boschin, B. Steen, P. Johansson, and M. R. Palacin, J. Mater. Chem. A, 3, 22 (2015).

13. J. Muldoon, C. B. Bucur, A. G. Oliver, T. Sugimoto, M. Matsui, H. S. Kim, G. D. Allred, J. Zajicek, and Y. Kotani, Energy Environ. Sci., 5, 5941 (2012).

14. J. H. Exner and E. C. Steiner, J. Am. Chem. Soc., 96, 1782 (1974).

15. M. J. Ziegler and J. D. Madura, J. Solution Chem., 40, 1383 (2011).

16. D. M. Seo, O. Borodin, S.-D. Han, Q. Ly, P. D. Boyle, and W. A. Henderson, J. Electrochem. Soc., 159, A553 (2012).

17. D. M. Seo, O. Borodin, S.-D. Han, P. D. Boyle, and W. A. Henderson, J. Electrochem. Soc.,159, A1489 (2012).

18. E. Jonsson and P. Johansson, Phys. Chem. Chem. Phys., 14, 10774 (2012).

19. M. Okoshi, Y. Yamada, A. Yamada, and H. Nakai, J. Electrochem. Soc., 160, A2160 (2013).

20. M. Ong, O. Verners, E. W. Draeger, A. C. T. van Duin, V. Lordi, and J. E. Pask, $J$. Phys. Chem. B, 119, 1535 (2014).

21. S. Kerisit, M. Vijayakumar, K. S. Han, and K. T. Mueller, J. Chem. Phys., 142, 224502 (2015).

22. M. Shakourian-Fard, G. Kamath, K. Smith, H. Xiong, and S. K. R. S. Sankaranarayanan, J. Phys. Chem. C, 119, 22747 (2015).

23. T. Kimura, K. Fujii, Y. Sato, M. Morita, and N. Yoshimoto, J. Phys. Chem. C, 119, 18911 (2015).

24. J. Wahlers, K. D. Fulfer, D. P. Harding, D. G. Kuroda, R. Kumar, and R. Jorn, J. Phys. Chem. C, 120, 17949 (2016).

25. P. Aldebert, M. Guglielmi, and M. Pineri, Polymer J., 23, 399 (1991)

26. D. Benrabah, S. Sylla, F. Alloin, J.-Y. Sanchez, and M. Armand, Electrochim. Acta, 40, 2259 (1995)

27. C. M. Doyle, M. E. Lewittes, M. G. Roelofs, S. A. Perusich, and R. E. Lowrey, $J$. Membrane Sci., 184, 257 (2001).

28. S. Sachan, C. A. Ray, and S. A. Perusich, Polym. Eng. Sci., 42, 1469 (2002).

29. W. Navarrini, B. Scrosati, S. Panero, A. Ghielmi, A. Sanguineti, and G. Geniram, J. Power Sources, 178, 783 (2008).

30. Zh. Jin, K. Xie, and X. Hong, J. Mater. Chem., 1, 342 (2013).

31. H. Cheng and K. Scott, Electrochim. Acta, 116, 51 (2014).

32. E. A. Sanginov, E. Yu. Evshchik, R. R. Kayumov, and Yu. A. Dobrovol'skii, Russ. J. Electrochem., 51, 986 (2015)

33. Q. Yu, Y. Nie, Y. Cui, J. Zhang, and F. Jiang, Electrochim. Acta, 182, 297 (2015). 
34. S. Burlatsky, R. M. Darling, D. Novikov, V. V. Atrazhev, V. I. Sultanov, T. Y. Astakhova, L. Su, and F. Brushett, J. Electrochem. Soc., 163, A2232 (2016).

35. D. Yu. Voropaeva, S. A. Novikova, T. L. Kulova, and A. B. Yaroslavtsev, Ionics, 24 1685 (2018).

36. J. Peng, M. K. Tian, N. M. Cantillo, and T. Zawodzinski, Electrochim. Acta, 282, 544 (2018).

37. T. Okada, G. Xie, O. Gorseth, S. Kjelstrup, N. Nakamura, and T. Arimura, Electrochim. Acta, 43, 3741 (1998).

38. S. Shi, A. Z. Webera, and A. Kusoglu, Electrochim. Acta, 220, 517 (2016).

39. D. Y. Voropaeva, S. A. Novikova, T. L. Kulova, and A. B. Yaroslavtsev, Solid State Ionics, 324, 28 (2018).

40. Z. Samec, A. Trojánek, J. Langmaier, and E. Samcová, J. Electrochem. Soc., 144, 4236 (1997).

41. E. A. Sanginov, R. R. Kayumov, L. V. Shmygleva, V. A. Lesnichaya, A. I. Karelin, and Yu. A. Dobrovolsky, Solid State Ionics, 300, 26 (2017).

42. K. Hongsirikarn, T. Napapruekchart, X. Mo, and J. G. Goodwin Jr,, J. Power Sources, 196, 644 (2011).

43. K. Hongsirikarn, J. G. Goodwin Jr., S. Greenway, and S. Creager, J. Power Sources, 195, 30 (2010).

44. R. Halseid, P. J. S. Vie, and R. Tunold, J. Electrochem. Soc., 151, A381 (2004).

45. H. L. Clever and E. F. Westrum Jr,, J. Phys. Chem., 74, 1309 (1970).

46. A. D. Becke, J. Chem. Phys., 98, 5648 (1993).

47. B. J. Johnson, P. M. W. Gill, and J. A. Pople, J. Chem. Phys., 98, 5612 (1993).

48. M. J. Frisch, G. W. Trucks, H. B. Schlegel, G. E. Scuseria, M. A. Robb J. R. Cheeseman, G. Scalmani, V. Barone, G. A. Petersson, H. Nakatsuji, X. Li, M. Caricato, A. Marenich, J. Bloino, B. G. Janesko, R. Gomperts, B. Mennucci, H. P. Hratchian, J. V. Ortiz, A. F. Izmaylov, J. L. Sonnenberg, D. Williams-Young, F. Ding, F. Lipparini, F. Egidi, J. Goings, B. Peng, A. Petrone, T. Henderson, D. Ranasinghe, V. G. Zakrzewski, J. Gao, N. Rega, G. Zheng, W. Liang, M. Hada M. Ehara, K. Toyota, R. Fukuda, J. Hasegawa, M. Ishida, T. Nakajima, Y. Honda, O. Kitao, H. Nakai, T. Vreven, K. Throssell, J. A. Montgomery Jr., J. E. Peralta,
F. Ogliaro, M. Bearpark, J. J. Heyd, E. Brothers, K. N. Kudin, V. N. Staroverov, T. Keith, R. Kobayashi, J. Normand, K. Raghavachari, A. Rendell, J. C. Burant, S. S. Iyengar, J. Tomasi, M. Cossi, J. M. Millam, M. Klene, C. Adamo, R. Cammi,

J. W. Ochterski, R. L. Martin, K. Morokuma, O. Farkas, J. B. Foresman, and D. J. Fox, Gaussian 09, Revision B.01; Gaussian, Inc.: Wallingford, CT, (2010). Gaussian 03, Revision C. 02. Gaussian, Inc., Wallingford CT, (2004).

49. G. Gebel, P. Aldebert, and M. Pineri, Polymer, 34, 333 (1993).

50. J. A. Elliott, S. Hanna, A. M. S. Elliott, and G. E. Cooley, Macromolecules, 33, 4161 (2000).

51. C. I. Filipoi, X. Zhu, D. Türp, R. A. Vinokur, D. E. Demco, R. Fechete, M. Moeller, O. Conradi, A. Graichen, D. Anokhin, and D. A. Ivanov, Int. J. Hydrogen Energ., 37, 14454 (2012).

52. H. S. Sodaye, P. K. Pujari, A. Goswami, and S. B. Manohar, J. Polym. Sci. Pol. Phys., 36, 983 (1998).

53. V. P. Shantarovich, I. B. Kevdina, Yu. P. Yampolskii, and A. Yu. Alentiev, Macromolecules, 33, 7453 (2000).

54. A. I. Karelin, R. R. Kayumov, E. A. Sanginov, and Yu. A. Dobrovolsky, Petroleum Chem., 56, 1020 (2016).

55. A. I. Karelin, R. R. Kayumov, E. A. Sanginov, and Yu. A. Dobrovolsky, Spectrochim. Acta A, 178, 94 (2017)

56. A. I. Karelin, R. R. Kayumov, and Yu. A. Dobrovolsky, Spectrochim. Acta A, 215, 381 (2019).

57. M. Fujimura, T. Hashimoto, and H. Kawai, Macromolecules, 14, 1309 (1981).

58. K. Schmidt-Rohr and Q. Chen, Nat. Mater., 7, 75 (2008).

59. K.-D. Kreuer and G. Portale, Adv. Func. Mater, 23, 5390 (2013)

60. H. Yoshida and Y. Miura, J. Membrane Sci., 68, 1 (1992).

61. S. J. Paddison and R. Pau, Phys. Chem. Chem. Phys., 4, 1158 (2002).

62. M. Saito, K. Hayamizu, and T. Okada, J. Phys. Chem. B, 109, 3112 (2005).

63. A. Siu, J. Schmeisser, and S. Holdcroft, J. Phys. Chem. B, 110, 6072 (2006)

64. A. Kusoglu and A. Z. Weber, Chem. Rev., 117, 987 (2017).

65. C. P. Kelly, C. J. Cramer, and D. G. Truhlar, J. Phys. Chem. B, 111, 408 (2007). 